\title{
Programas de Pós-Graduação em Serviço Social no Brasil: tendências das áreas de concentração, linhas de pesquisa e disciplinas
}

\author{
Graduate programs in Social Work in Brazil: trends focus areas, \\ research areas and disciplines
}

\author{
Jane Cruz Prates* \\ Thaisa Teixeira Closs** \\ Gissele Carraro***
}

\begin{abstract}
Resumo:
O estudo apresentado neste artigo tem como objetivo identificar tendências em relação à estruturação dos Programas de Pós-Graduação em Serviço Social no Brasil, com ênfase na análise da organização das áreas de concentração, linhas de pesquisa e oferta de disciplinas, de modo a levantar os temas mais abordados nos processos investigativos e formativos nos programas existentes no país. O estudo foi desenvolvido por meio de pesquisa documental, através da construção de Banco de Dados, que sistematiza informações da CAPES, e de sítios eletrônicos dos programas. Os resultados evidenciam a prevalência das temáticas: Política Social, Questão Social e Trabalho, articuladas ao debate da profissão, como as principais tendências de pesquisa e formação nesse nível de ensino.
\end{abstract}

Palavras-chave: Serviço social. Pós-graduação. Formação profissional.

\begin{abstract}
:
The article aims to identify trends in the structuring of Post-Graduate Programs in Social Work in Brazil, with emphasis on the analysis of the organization of the areas of concentration, research lines and offer of disciplines, analyzing the most discussed subjects in research processes and formation in existing programs in the country. The study was conducted through documentary research, by building database that organizes information from CAPES and websites of post-graduate programs. The results shows the prevalence of thematic: Social Policy, Social Issue and Work, articulated to the debate of the profession, as the main trends in research and formation in that level of education.
\end{abstract}

Keywords: Social work. Graduate programs. Vocational training.

\footnotetext{
* Pontifícia Universidade Católica do Rio Grande do Sul (PUCRS). Assistente Social, mestre e doutora em Serviço Social. E-mail: jprates@pucrs.br

** Pontifícia Universidade Católica do Rio Grande do Sul (PUCRS). Assistente Social, mestre e doutora em Serviço Social. E-mail: thaisacloss@hotmail.com

${ }^{* * *}$ Assistente Social, mestre e doutora em Serviço Social. E-mail: gcarraro25@gmail.com
} 


\section{Introdução}

A institucionalização da pós-graduação, no Brasil, teve como marco inicial a criação da Coordenação de Aperfeiçoamento de Pessoal de Nível Superior (CAPES) ${ }^{1}$, por meio do Decreto no 29.741, de 11 de julho de 1951, que cumpriu um papel importante, especialmente, no que tange à educação superior, uma vez que contribui para a formulação de políticas. Tem, ainda, a função de coordenar o sistema nesse nível de ensino, bem como, avaliar os cursos de mestrado e doutorado, estimulando, por meio de bolsas de estudo, auxílios e outros subsídios, a formação de recursos humanos qualificados para a docência em grau superior, a pesquisa e o atendimento às demandas dos setores público e privado (BRASIL, 2012).

A partir das informações produzidas e publicizadas sobre a pós-graduação no país, realizou-se uma pesquisa documental sobre os Programas de Pós-Graduação em Serviço Social (PPGSS), na plataforma Sucupira da CAPES (PLATAFORMA SUCUPIRA, 2016), que resultou em um Banco de Dados. Este reúne informações sobre as áreas de concentração, as linhas de pesquisa, as disciplinas ofertadas e os grupos e núcleos de pesquisa vinculados às IES que ofertam os Cursos de Mestrado e Doutorado. Com relação às disciplinas oferecidas, foram utilizadas, como fonte de dados, as Informações do Programa, especificamente, Disciplinas ${ }^{2}$, do item Consultas, de cada PPGSS.

Nessa direção, o estudo buscou identificar tendências quanto à estruturação das áreas de concentração, linhas de pesquisa e disciplinas, por meio do mapeamento dos conteúdos preponderantes na formação e pesquisa nesse nível de formação. Trata-se de uma análise preliminar do referido banco de dados sistematizado, que será aprofundada em outras produções científicas, especialmente, no que se refere à discussão e análise de ementas das disciplinas dos PPGSS. Assim, inicialmente, são apresentados os temas predominantes na estruturação das áreas e linhas de pesquisa, para, posteriormente, analisar as tendências da organização das matrizes curriculares nos Cursos de Mestrado

\footnotetext{
${ }^{1}$ Esta é uma fundação pública, vinculada ao Ministério da Educação, responsável por subsidiar a formulação de políticas e o desenvolvimento de atividades de suporte à formação de profissionais de magistério para a educação básica e superior e o desenvolvimento científico e tecnológico do País (BRASIL, 2012).

2 Neste item, estão registradas as disciplinas ofertadas a partir de um ano base (2012-2016), tais como: disciplina, curso (mestrado e/ou doutorado), classificação (obrigatória e/ou optativa), carga horária, créditos, ementas, bibliografia.
} 
Acadêmico e Doutorado em Serviço Social. Frisa-se que as reflexões tecidas, nesse trabalho, concentram-se nos programas, especificamente, da área básica de Serviço Social.

\section{Estruturação das áreas e linhas de pesquisa dos programas de Pós-graduação em}

\section{Serviço Social}

O ponto de partida da análise da estruturação das áreas e linhas de pesquisa dos PPGSS pressupõe situar sua institucionalização e o desenvolvimento da formação profissional nesse nível de ensino no Brasil. Tal processo teve início na década de 1970, em plena vigência da ditadura militar no país (1964-1980), quando foram estabelecidos os primeiros cursos de mestrado: i) em 1972, na PUC/SP e PUC/RJ; ii) em 1976, na UFRJ; iii) em 1977, na PUCRS; iv) em 1978, na UFPB; v) em 1979, na UFPE. (KAMEYAMA, 1998). Esse processo prosseguiu nas décadas de 1980, 1990 e 2000, com a criação de novos cursos de mestrado e doutorado, em instituições de ensino superior de diferentes regiões do país. Sem dúvida, tal processo, significou, para a profissão, um importante avanço, uma vez que:

[...] foi uma expressão de rompimento com a postura positivista que determinava a separação do pensar e do agir, do construir conhecimento, do intervir na realidade social. Essa forma de pensar orientou, durante décadas, o pensamento profissional e situou os assistentes sociais no estágio de meros sujeitos de intervenção profissional e consumidores de teorias onstruídas por outras disciplinas profissionais (YAZBEK; SILVA, 2005, p. 44).

Nesse sentido, torna-se fundamental mencionar que o avanço da pós-graduação na área, no Brasil, inscreve-se no processo de delineamento do projeto ético-político profissional - comprometido com os interesses das classes trabalhadoras e com o processo de redemocratização da sociedade brasileira -, de ruptura com o conservadorismo que marcou a profissão até a década de 1980. A partir dos anos de 1980 e avançando em 1990, a área vem efetivando a interlocução da teoria social crítica de Marx com a profissão. Ressalta-se que a adoção deste referencial:

[...] vai imprimir direção ao pensamento e à ação do Serviço Social no país. Vai permear as ações voltadas à formação de assistentes sociais na sociedade brasileira (o currículo de 1982 e as atuais diretrizes curriculares); os eventos acadêmicos e aqueles resultantes da experiência associativa dos profissionais, como suas Convenções, Congressos, Encontros e Seminários; está presente na regulamentação legal do exercício profissional e em seu Código de Ética. Sob sua 
influência ganha visibilidade um novo momento e uma nova qualidade no processo de recriação da profissão na busca de sua ruptura com seu histórico conservadorismo (cf. NETTO, 1996, p. 111) e no avanço da produção de conhecimentos, nos quais a tradição marxista aparece hegemonicamente como uma das referências básicas (YAZBEK, 2009, p. 154).

É interessante observar que a prevalência e a direção da teoria social crítica na formação, no exercício profissional e na produção de conhecimentos científicos, na área do Serviço Social brasileiro, constituiu-se a partir de um amplo "embate e debate [plural] entre as diferentes correntes de pensamento e da ação humana." (ABREU, 2007, p. 121). Assim, se reconhece que a profissão tem avançado, expressivamente, ao longo das últimas décadas, em um empenho intensivo no sentido do adensamento crítico e atualização da teoria metodológica, que pode ser evidenciado no:

[...] significativo crescimento e produtividade da pós-graduação referente à área do Serviço Social tem suprido a área da graduação com pesquisas, periódicos e livros, que são fundamentais à formação dos profissionais da área, debatendo os mais diversos temas, enfrentando polêmicas, posicionando-se por meio do conjunto Conselho Federal de Serviço Social (CFESS)/Conselho Regional de Serviço Social (CRESS) e da Associação Brasileira de Escolas de Serviço Social (ABEPSS), participando de lutas por direitos, contribuindo na constituição e na qualificação de políticas públicas, nos seus processos de avaliação, no debate acerca do Estado, do fundo público, da gestão pública, do controle social e dos movimentos sociais (PRATES, 2015, p. 3).

Dessa forma, é evidente que a formação profissional de pós-graduação constitui-se como lócus privilegiado para a produção de conhecimentos, formação e qualificação de docentes, pesquisadores e profissionais para a pesquisa, ensino e exercício profissional. Contudo, não se pode perder de vista que o processo de conformação desse nível educacional, na contemporaneidade, vem, necessariamente, passando por significativas alterações, que o sintoniza com os interesses do grande capital à medida que:

[...] se destaca como uma área de ensino estratégica para que os países se integrem de forma mais competitiva no cenário global. O crescimento da pósgraduação no Brasil situa-se, portanto, nesse contexto em que o país procura se inserir competitivamente no mercado mundial, em que a produção de conhecimento e sua aplicabilidade em forma de tecnologia e produtos sociais se tornam um imperativo (CABRAL NETO; CASTRO, 2013, p. 350-351). 
Tal fato vai afetar - haja vista o processo de contrarreforma ${ }^{3}$ em andamento no Brasil desde a década de 1990 -, o ensino superior de graduação e pós-graduação, impactando: i) os processos de gestão das instituições de ensino, que passam a ser moldadas pela lógica empresarial; ii) os processos pedagógicos implementados, que afetam a organização das disciplinas e, consequentemente, seus conteúdos, através da flexibilização curricular em uma perspectiva mercadológica; iii) o desenvolvimento da pesquisa e a produção de conhecimentos que são direcionados para uma perspectiva produtivista; iv) a direção social da formação, que se depara com o tecnicismo instrumental ao invés de uma direção crítica; v) as condições e relações de trabalho dos docentes, por meio da precarização, intensificação, flexibilização e desqualificação.

Diante disso, o grande desafio que se coloca, hoje, para o Serviço Social, no espaço das instituições de ensino superior, em nível de graduação e pós-graduação, é o de remar contra a corrente (COUTINHO, 2000), ou seja, de "garantir uma formação profissional de qualidade", que defenda "a perspectiva de mobilização em torno da construção de outra sociabilidade" (RAMOS, 2007, p. 169). Isso, sem dúvida, exige "uma grande envergadura teórica e racionalidade política" (SILVA, 2010, p. 428), que tem sido constituída pela área, através do acúmulo e do avanço, em termos de produção de conhecimentos, pesquisa e participação em espaços políticos organizativos da profissão e da sociedade.

É nesse contexto que se tem colocado a possibilidade de expansão e amadurecimento da formação profissional, em nível de pós-graduação, no Serviço Social, no Brasil, notadamente, nas últimas duas décadas. Se for apreciado somente o período mais recente, em 2004, a área contava com 18 cursos, em 2007, estes já totalizavam 24, e, em 2012, 30 Programas. Assim, em relação à década de 1990, obteve-se um crescimento de mais de $100 \%$ dos PPGSS (PRATES et al., 2012).

\footnotetext{
3 Para se afirmar que se trata de uma contrarreforma, entende-se como primordial conceituar o que é reforma: "[...] na tradição filosófica ocidental, sempre teve uma conotação de caráter progressista, em uma direção de maior igualdade e liberdade. O termo começa a ser usado a partir da reforma Protestante, que foi considerada um enorme avanço às liberdades individuais, uma vez que possibilitou o diálogo direto dos crentes com seu deus. Desde então, na tradição política ocidental, falar de reformas sempre significou um processo de troca para uma sociedade mais igualitária, uma sociedade mais justa, uma sociedade potencialmente mais democrática. Sem dúvida, as reformas [...] que tiveram lugar na América Latina se moveram exatamente em direção contrária. Por isso, mais que reformas, o termo mais correto seria dizer que foram processos de contra-reforma, processos de destruição, processos que tiveram como conseqüência processos de des-cidadanização" (BÓRON, 2003, p. 33-34, tradução e grifo nosso).
} 
Neste processo de ampliação e consolidação, é fundamental ressaltar a relação entre pós-graduação e produção do conhecimento, especialmente, frente ao processo de renovação crítica do Serviço Social, no qual, a área:

[...] vem dialogando e se apropriando das Teorias Sociais e do debate intelectual contemporâneo, no âmbito das ciências sociais no país e no exterior. Também nesse espaço (da pós-graduação), o Serviço Social brasileiro desenvolveu-se na pesquisa acerca de seus fundamentos, da natureza da sua intervenção, de seus procedimentos, de sua formação, de sua história e, sobretudo acerca da realidade social, política, econômica e cultural onde se insere como profissão na divisão social e técnica do trabalho. Avançou na pesquisa da questão social, do Estado capitalista, das políticas sociais, dos movimentos sociais, dos direitos sociais, da cidadania, da democracia, do processo de trabalho e de suas transformações, da realidade institucional, das múltiplas faces da exclusão social e da pobreza e de outros temas (YAZBEK, 2009, p. 152).

Tais eixos de pesquisa e produção de conhecimento, que perpassam a pósgraduação, segundo a autora, evidenciam o compromisso dessa profissão em produzir conhecimentos que: desvendem a realidade; atualizem possibilidades inovadoras de trabalho, compromissadas com processos emancipatórios; e adensem e qualifiquem a formação na graduação.

Atualmente, a área de Serviço Social conta com um total de 34 programas de pósgraduação, sendo um (01) de Economia Doméstica e os demais (33) desenvolvidos, prioritariamente, nas áreas de: Serviço Social (61,76\%), Política (s) Social (is)/Políticas Públicas (23,52\%), Serviço Social e Política Social (5,9\%), Política Social e Serviço Social (2,94\%), e Economia Doméstica (2,94\%). Vale referir que a área básica de Serviço Social agrega Programas com outras matérias relacionadas, quais sejam: Serviço Social e Desenvolvimento Regional (UFF) e Serviço Social, Trabalho e Questão Social (UECE). Já a área básica de Política Social/Política Pública agrega a temática do desenvolvimento local.

A maioria dos programas da área básica de Serviço Social oferta somente cursos de mestrado (52,38\%), sendo que $47,62 \%$ dos programas possuem cursos de mestrado $e$ doutorado. O primeiro grupo de programas situa-se, predominante, na região nordeste $(54,54 \%)$, seguida dos programas das regiões sudeste $(18,18 \%)$, norte, sul e centro-oeste, cada uma representando 9,09\%. Já os programas de mestrado e doutorado situam-se, predominantemente, na região sudeste $(50 \%)$, seguida da região sul e nordeste (perfazendo $20 \%$ cada) e, em pequena escala, na norte (10\%). 
Em relação à natureza das instituições, sublinha-se que a ampla maioria dos programas é ofertada em instituições públicas - inverso da graduação - e, dentre as instituições privadas que desenvolvem cursos de mestrado e/ou doutorado, em sua totalidade, são as Pontifícias Universidades Católicas (PUC-SP, PUC-RIO, PUCRS, PUCGOIÁS). No quadro 1, são apresentados os PPGSS vinculados à área de Serviço Social.

Quadro 1 - Programas de Pós-Graduação vinculados à área de Serviço Social

\begin{tabular}{|l|l|l|}
\hline Cursos ofertados & Instituições & Unidade Federal \\
\hline Mestrado em Serviço Social & $\begin{array}{l}\text { PUC-GOIÁS, UFPB/J.P, UFAL, FUFSE, } \\
\text { UEPB, UFAM, UFJF, UNIOSTE }\end{array}$ & $\begin{array}{l}\text { GO, PB, AL, SE, PB, AM, RJ, } \\
\text { PR }\end{array}$ \\
\hline $\begin{array}{l}\text { Mestrado em Serviço Social e } \\
\text { Desenvolvimento Regional }\end{array}$ & UFF RJ & RJ Social, \\
\hline $\begin{array}{l}\text { Mestrado em Serviço } \\
\text { Trabalho e Questão Social }\end{array}$ & UECE \\
\hline $\begin{array}{l}\text { Mestrado em Serviço Social e } \\
\text { Direitos Sociais }\end{array}$ & UERN & RN \\
\hline $\begin{array}{l}\text { Mestrado em Serviço Social e } \\
\text { Política (s) Social(is) }\end{array}$ & UNIFESP & SP \\
\hline $\begin{array}{l}\text { Mestrado e Doutorado em Serviço } \\
\text { Social e Política Social }\end{array}$ & UEL & PR \\
\hline $\begin{array}{l}\text { Mestrado e Doutorado em Serviço } \\
\text { Social }\end{array}$ & UFPA, UFRN, UFPE, UERJ, PUCSP, & PA, RN, PE, RJ, SP, SP, RJ, RJ, \\
\hline $\begin{array}{l}\text { Mestrado em Política Social } \\
\text { UNESP/FR, PUC-RIO, UFRJ, UFSC, PUCRS }\end{array}$ & UFTM RS & MT \\
\hline $\begin{array}{l}\text { Mestrado em Política Social e } \\
\text { Serviço Social }\end{array}$ & UFRGS & RS \\
\hline $\begin{array}{l}\text { Mestrado e Doutorado em Política } \\
\text { Social/ Políticas Públicas }\end{array}$ & UNB, UFES, UFF, UFMA, FUFPI, UCPEL & DF, ES, RJ, MA, PI, RS \\
\hline $\begin{array}{l}\text { Mestrado em Políticas Públicas e } \\
\text { Desenvolvimento Local }\end{array}$ & EMESCAM & ES \\
\hline $\begin{array}{l}\text { Mestrado e Doutorado em } \\
\text { Economia Doméstica }\end{array}$ & UFV & MG \\
\hline
\end{tabular}

Fonte: Sistematização das autoras a partir da Plataforma Sucupira (2016).

A investigação sobre os programas de pós-graduação visou a identificar as tendências temáticas da estruturação dos mesmos, com realce para a organização das áreas de concentração, linhas de pesquisa e oferta de disciplinas. A partir do banco de dados construído, constatou-se que o conjunto dos 21 programas em Serviço Social apresenta 25 áreas de concentração, sendo que, quase em sua totalidade (20 de 21 programas), apresentam o tema Serviço Social na denominação de suas áreas ${ }^{4}$.

\footnotetext{
4 Este dado refere-se ao programa da UERJ, que possui como área de concentração "Trabalho e Política
} Social". 
Do conjunto de áreas de concentração, apenas duas (02) delas são idênticas em mais de um programa, quais sejam: Política Social (UEL e UFPB), Serviço Social, Questão Social e Direitos Sociais (UEPB e PUC-RIO) e Serviço Social, Política Social e Movimentos Sociais (PUC-SP e PUC-GOIÁS). Após a análise realizada, buscou-se identificar a incidência de matérias na totalidade das áreas de concentração, com o objetivo de mapear as tendências de formação e pesquisa, dado que se encontra sistematizado no quadro a seguir.

Quadro 2 - Temáticas das áreas de concentração dos PPGSS

\begin{tabular}{|l|l|c|}
\hline \multicolumn{1}{|c|}{$\begin{array}{c}\text { Especificação das temáticas nas } \\
\text { áreas de concentração dos } \\
\text { programas }\end{array}$} & Programas em que a temática está presente & Freq. \\
\hline $\begin{array}{l}\text { Política (s) Social (is)/Políticas } \\
\text { Públicas }\end{array}$ & $\begin{array}{l}\text { UFAM, UERJ, UEL, PUCRS, UFJF, UFF, UFRJ, PUCSP, FUFSE, } \\
\text { UFRN, PUC-GOIÁS, UFPB, UFPA, UNIOESTE }\end{array}$ & 14 \\
\hline Direitos/Cidadania & UFAL, UFPE, UERN, UNIOESTE, UEPB, UFSC, UFRJ, PUC-RIO & 08 \\
\hline Questão Social & UFRJ, PUC-RIO, UFJF, UEPB, UFSC. & 05 \\
\hline Movimentos e processos sociais & PUCSP, PUC-GOIÁS, UFPE, PUCRS. & 04 \\
\hline $\begin{array}{l}\text { Temáticas com menor } \\
\text { incidência } 5 \text { UERJ, UFAL, UNESP/FR, PUCSP, UFPB/J.P, UFPA, UFF. }\end{array}$ & 07 \\
\hline $\begin{array}{l}\text { Temáticas com frequência única } \\
6\end{array}$ & UFJF, UFAM, UFRJ, PUCSP, UFRN, UNESP. & 06 \\
\hline
\end{tabular}

Fonte: Sistematização das autoras a partir da Plataforma Sucupira (2016).

Com base nos dados do Quadro 2, salienta-se que a inclinação majoritária das áreas de concentração dos programas de Serviço Social, no Brasil, é para tema Política (s) Social (is)/Políticas Públicas, presente em 14 dos 21 PPGSS, seguido de Direitos/Cidadania, Questão Social, e, na sequência, por Movimentos e Processos Sociais.

Embora a área de Serviço Social disponha de percentual significativo de programas em Política Social/Política Pública, verifica-se a forte presença deste tema nos PPGSS. Em uma perspectiva histórica, isso se mantém desde a década passada, pois estudo realizado por Silva e Silva et al. (2005, p. 89) aponta que Política Social/Políticas Públicas/Avaliação de Políticas Sociais possui a maior ocorrência nas áreas de concentração e linhas de pesquisa. Tal ênfase, relaciona-se, portanto, com o vínculo histórico do Serviço Social com as políticas sociais, especialmente, em seu protagonismo no debate da Seguridade Social

\footnotetext{
${ }^{5}$ As temáticas com menor frequência foram agrupadas pelo número de pontuações, de 2 a 3 vezes, sendo: fundamentos (03), desenvolvimento (02) e trabalho (03).

6 Temáticas com incidência única nas áreas de concentração dos programas: território, sustentabilidade e Amazônia, cultura, prática profissional, sociabilidade e sociedade.
} 
brasileira - em uma conjuntura que coincide com o processo de consolidação e expansão da pós-graduação da área - bem como, por ser este o maior universo sócio-ocupacional dessa profissão.

Observa-se, ainda, o destaque para a Questão Social, o que evidencia a centralidade que o debate deste tema assume na produção da área, seja como eixo da compreensão das próprias políticas sociais, como base sócio-histórica do Serviço Social e objeto de trabalho, ou como elemento central das diretrizes curriculares da ABEPSS (ASSOCIAÇÃO BRASILEIRA DE ENSINO E PESQUISA EM SERVIÇO SOCIAL; CENTRO DE DOCUMENTAÇÃO E PESQUISA EM POLÍTICAS SOCIAIS E SERVIÇO SOCIAL, 1996) para a formação e exercício profissional. Em termos históricos, conforme o mesmo estudo (SILVA E SILVA et al., 2005), nota-se um aumento significativo da presença deste tema nas áreas e linhas de pesquisa. Já as demais temáticas, especialmente, Trabalho e Fundamentos, teriam, no espaço dos PPGSS, o lugar por excelência para seu aprofundamento, inclusive, tendo em vista o adensamento das produções sobre o exercício e a formação profissional, bem como, sobre as matrizes teórico-metodológicas e suas repercussões na produção de conhecimento.

Emanam, das áreas de concentração, as linhas de pesquisa, que totalizam sessenta e oito (68), diante dos vinte e um (21) PPGSS analisados. Dentre tais linhas, apenas duas (02) são idênticas em mais de um programa: Teoria Social e Serviço Social (UFRJ e PUC-Goiás); Serviço Social, Trabalho e Questão Social (UFRN e UFPE). Além das linhas idênticas, há as que apresentam grande similaridade entre alguns programas.

A primeira delas é a que conjuga Formação e Trabalho/Prática Profissional do Serviço Social ( 3 dos 21 programas), embora com magnitudes diferenciadas ${ }^{7}$. A segunda linha de pesquisa semelhante entre os programas é a que conjuga Política Social/Políticas Públicas e Movimentos Sociais com o Serviço Social (02 de 21 programas) ${ }^{8}$.

Quanto à análise geral da incidência das matérias nas linhas de pesquisa, menos da metade destas $(42,10 \%)$ não possui Serviço Social em suas denominações, constatando-se

\footnotetext{
${ }^{7}$ Esta similaridade foi identificada entre os seguintes programas e suas linhas de pesquisa: FUFSE - "Trabalho, formação profissional e Serviço Social"; PUCSP - "Pesquisa em Serviço Social: Identidade, formação e prática"; UNESP "Serviço Social: formação e prática profissional".

${ }^{8}$ Quais sejam: FUFSE - Políticas Sociais, Movimentos Sociais e Serviço Social; e UFPA - Serviço Social, Políticas Públicas e Movimentos Sociais.
} 
uma diversidade de temas de pesquisa nos programas, dado que se encontra sistematizado no Quadro 3, a seguir:

Quadro 3 - Temáticas das linhas de pesquisa dos PPGSS

\begin{tabular}{|l|l|c|}
\hline \multicolumn{1}{|c|}{ Especificação das temáticas } & \multicolumn{1}{|c|}{ Programas em que a temática está presente } & Freq. \\
\hline $\begin{array}{l}\text { Política(s) Social(is)/Políticas } \\
\text { públicas }\end{array}$ & $\begin{array}{l}\text { UFPE, UECE, UNIOESTE, UERN (2), PUC-GOIÁS, UFPB/J.P (4), } \\
\text { UFAM, UERJ (2), UEL, PUCRS, UFRJ, PUCSP, PUCRIO (2), FUFSE, } \\
\text { UFPA, UFJF, UFF, UNESP/FR (2), UEPB, UFRN, UFSC. }\end{array}$ & 28 \\
\hline Trabalho/processos de trabalho & $\begin{array}{l}\text { UNIOSTE, UFPE, UECE, UECE, UFRJ, PUCRIO, FUFSE, UFPA, UFAM, } \\
\text { UERJ, UEL, PUCRS, UFAL, UFPB/J.P, UEPB, UFRN, UFSC, UNESP/FR. }\end{array}$ & 18 \\
\hline $\begin{array}{l}\text { Direitos/Direitos Sociais/Direitos } \\
\text { humanos/Cidadania }\end{array}$ & $\begin{array}{l}\text { UFPB/J.P (2), UFPE (2), UFRJ, PUCRIO, UFAM, PUCGO, UFAL, } \\
\text { UNIOSTE, UERN, UFSC, UFRN. }\end{array}$ & 13 \\
\hline Questão Social & UFAM, UERJ, UFAL, UFPE, UECE, UFSC, UERN, UFRN. & 08 \\
\hline Formação profissional & PUCSP, FUFSE, UFF, UFPB/J.P, UFSC, UNESP/FR. & 06 \\
\hline Estado & UFRJ, PUCSP, UFPB/J.P, UECE, UEPB, UFRN. & 06 \\
\hline Movimentos Sociais & PUC-GOIÁS, PUCSP, UFRJ, FUFSE, UFPA, UERN. & 06 \\
\hline Gestão & UFJF, UEL, UFPB/J.P (2). & 04 \\
\hline
\end{tabular}

Fonte: Sistematização das autoras a partir da Plataforma Sucupira (2016).

Considera-se importante a articulação destes dados com os sistematizados no Quadro 2, para que seja possível identificar a relação entre áreas de concentração e linhas de pesquisa. Nesse sentido, a coerência entre as áreas de concentração, as linhas de pesquisa e a proposta curricular dos programas é um dos quesitos apreciados na avaliação da CAPES para a área. Verifica-se, assim, que o tema Política (s) social(is)/Políticas Públicas figura como central, tanto nas áreas como nas linhas pesquisa.

A seguir, visualiza-se que a proeminência para o Trabalho/Processos de Trabalho temática que não possui incidência significativa nas áreas dos PPGSS - apresenta-se como a segunda principal tendência entre as linhas de pesquisa, seguida, logo após, de ênfases presentes nas áreas de concentração, embora com pequena mudança em ordem de presença (Direitos/Cidadania, Questão Social, Movimentos e Processos Sociais).

Observa-se, ainda, a emergência de novos temas não presentes nas referidas áreas: a Formação Profissional, o destaque para o Estado e, ainda, a Gestão. É relevante enfatizar a importância das áreas de concentração e linhas de pesquisa na estruturação dos PPGSS, uma vez que estas "são eixos geradores e articuladores dos Planos de Cursos, dos projetos pedagógicos e das atividades de pesquisa e produção de conhecimento nos Programas de Pós-Graduação" (SILVA E SILVA; CARVALHO, 2007, p. 203). Portanto, orientaram, 
diretamente, a organização das matrizes curriculares do Mestrado e do Doutorado, cujas tendências, no que se refere às temáticas das disciplinas ofertadas, serão abordadas na próxima seção do artigo.

Salienta-se, dos dados analisados, o direcionamento da produção e da pósgraduação para o debate da política social, o que merece considerações. São inegáveis as contribuições que este eixo de investigação da área aporta para a análise crítica da Seguridade Social brasileira e mesmo para a politização do exercício profissional. (IAMAMOTO, 2005).

Contudo, lamamoto (2005, p. 242) identifica um dilema de duas faces que perpassa essa tônica da produção, qual seja: por um lado, "um relativo obscurecimento das transformações operadas na sociedade civil [...], que na literatura profissional passou a ser filtrada através das estratégias do Estado e ações dos governos" e, por outro, uma "relação mimética entre Serviço Social e política social, submergindo a visibilidade das respostas profissionais no âmbito dessas políticas." (IAMAMOTO, 2005, p. 242).

Merece importante atenção esse dilema, pois é um desafio que perpassa a agenda de pesquisa da área. Na esteira desse desafio, inclusive, situa-se a diminuta abordagem dos Fundamentos do Serviço Social no campo da estruturação das áreas de concentração dos programas e linhas de pesquisa. Infere-se que isso impacta também a produção de conhecimento sobre o tema, pois, pesquisa realizada por Closs (2015) - a partir da análise de 226 volumes dos periódicos de 11 revistas, totalizando 2031 artigos revisados identificou que as publicações que possuem o descritor Fundamentos do Serviço Social são, extremamente, reduzidas, perfazendo $0,49 \%$ dos artigos publicados nas principais revistas ${ }^{9}$ da área, vinculadas aos PPGSS.

Embora a área conte com uma rica literatura sobre esse tema, com pesquisadores que formularam teses distintas e fundamentais para a compreensão do significado social e da particularidade dessa profissão em sua trajetória sócio-histórica (ABREU, 2002; IAMAMATO \& CARVALHO, 2012; IAMAMOTO, 2005; MARTINELLI, 2003; NETTO, 2004, 2011; YAZBEK, 2009), questiona-se: Em que medida essas fecundas formulações vêm sendo

\footnotetext{
${ }^{9}$ Quais sejam: Em pauta (UERJ), Katálysis (UFSC), Libertas (UFFJ), O social em questão (PUC-RIO), Praia Vermelha (UFRJ), Serviço Social e Realidade (UNESP- Franca), Serviço Social em Revista (UEL), Textos e Contextos (PUCRS), Teoria Política e Social (UFPB), Temporalis (ABEPSS), Serviço Social \& Sociedade (Editora Cortez).
} 
aprofundadas, desdobradas em análises que adensem o debate dos Fundamentos, ou ainda, como essas teses vêm se expressando nas produções recentes? Na trilha deste questionamento, sinaliza lamamoto (2008, p. 244):

[...] são parcas as produções recentes que têm o Serviço Social como objeto de suas pesquisas, podendo sugerir uma armadilha: a incorporação, pelos próprios pesquisadores, de uma imagem social subalternizada da profissão, redundando numa relação envergonhada com o Serviço Social, não assumida como tal, e encoberta na busca de temas considerados de maior relevo acadêmico e social como objeto das investigações.

Mesmo que essas produções sejam parcas, os dados analisados indicam um relevante direcionamento dos programas de pós-graduação para o Trabalho e a Questão Social. No que se refere à Questão Social, sua abordagem nos programas de pós-graduação aponta a centralidade desta categoria teórica - que, resignificada do universo do pensamento conservador, a partir do referencial marxista - "se tornou uma espécie de 'patrimônio intelectual' dos assistentes sociais" (SANTOS, 2012, p. 431). Entretanto, cabe indagar: Como este "patrimônio" vem se expressando e se desenvolvendo nas investigações da área?

Se são amplas e consolidadas as abordagens que aprofundam a dimensão teórica desse conceito central para a profissão - inclusive, explicitando tônicas diferentes em sua compreensão -, permanecem como um desafio em aberto investigações que estabelecem mediações mais sistemáticas com o trato da questão social no campo do exercício e da formação profissional, na apreensão e respostas empreendidas pelos assistentes sociais às suas múltiplas expressões, bem como, no tratamento amplo da mesma no ensino, considerando-se as diminutas produções, nos periódicos da área, que se referem, diretamente, a este tema (CLOSS, 2015).

No que tange ao Trabalho e sua abordagem na pós-graduação, identifica-se que este tema pode ir ao encontro de uma exigência contemporânea da pesquisa da área, qual seja, a de aprofundar o debate sobre "o processamento do trabalho profissional cotidiano, na efetivação das competências e atribuições profissionais, e às estratégias de sua implementação - como há largo tempo vem sendo requisitado pela categoria" (IAMAMOTO, 2008, p. 239). Na esteira dessa exigência, indaga-se: Sob que ângulos vem 
ocorrendo o debate sobre o trabalho profissional e sobre as profundas transformações na esfera do mundo do trabalho, processadas nas últimas décadas?

No trato do Trabalho Profissional, identifica-se a propensão de pesquisas que, frequentemente, não conseguem "trabalhar a universalidade contida no singular" (YAZBEK, 2005, p. 155), recaindo na sistematização de experiências desconectadas do debate mais amplo da realidade que conforma o próprio trabalho profissional, ou ainda, uma "tendência ao pragmatismo", com a busca restrita por "avaliar os modelos e/ou procedimentos técnicos-operativos, objetivando subsidiar direta ou indiretamente a prática profissional." (KAMEYAMA, 1998, p. 25). Em sentido inverso, mas carecendo de mediações, situam-se as análises sobre as transformações macrossocietárias, que, sob a centralidade da categoria trabalho, não estabelecem a "'viagem de retorno à profissão', para reconstruí-las nas suas múltiplas relações e determinações como 'concreto pensado'." (IAMAMOTO, 2008, p. 240).

Assim, destaca-se a importância de conectar a análise das transformações no mundo do trabalho, que conta com densas produções da área, com o universo sócio-ocupacional da profissão, com foco para a flexibilização, a precarização e a terceirização do trabalho, que assumem contornos inéditos no Serviço Social, inclusive, frente à lacuna de estudos mais abrangentes e atuais sobre o mercado de trabalho dessa profissão.

Percebe-se uma proeminência de produções sobre Trabalho e Serviço Social nos periódicos da área (CLOSS, 2015). Contudo, uma angulação que precisa ser adensada nas pesquisas é, justamente, a ênfase para o/a assistente social como um trabalhador assalariado, atribuindo maior visibilidade e colocando em cena o assistente social e os impactos das condições de trabalho nos processos de alienação e adoecimento. Além disso, nesse debate, se sobressaem as categorias teóricas autônomas relativas às competências profissionais, uma vez que permitem maior visibilidade às possibilidades de materialização do projeto profissional e a conjugação dos Fundamentos no exercício profissional.

Dessa forma, a ênfase para a "Questão Social" e o "Trabalho" nos programas de pósgraduadação, mediadas com a análise do Serviço Social, é fundamental para que a qualificação do conhecimento da área, no plano macroestrutural, não se distancie da relação com a profissão, com sua dimensão interventiva, como já destacou Simionatto 
(2005), que apontou, inclusive, a existência de um hiato entre a produção dos grupos de pesquisa e as exigências do campo profissional.

Como sinaliza lamamoto (2008, p. 241), trata-se de articular "os fundamentos teórico-metodológicos com a pesquisa concreta de situações concretas", iluminando possibilidades de trabalho e de qualificação da formação profissional, bem como, aprofundando o conhecimento sobre a população usuária e as refrações da questão social, em seus modos e condições de vida e nas formas de resistências sociais empreendidas cotidianamente. Questões estas que não podem estar dissociadas da análise da particularidade da formação sócio-histórica brasileira e dos estudos do Brasil contemporâneo, como sublinha a autora (IAMAMOTO, 2008), além de se articularem com a importância do acompanhamento dos movimentos sociais emergentes na sociedade, tema que se sobressai nas áreas de concetração dos PPGSS e, em menor escala, nas linhas de pesquisa.

\section{Tendencias da organização das matrizes curriculares nos programas de Pós- graudação em Serviço Social}

A organização curricular implica, necessariamente, a escolha de um referencial teórico-metodológico e ético-político que fundamente a direção social da formação, materializada pela área do Serviço Social, pelo horizonte da qualificação de pesquisadores, docentes e profissionais, no campo da investigação, do ensino e do trabalho profissional, assim como, na promoção da produção de conhecimentos. É preciso ressaltar que a direção social é dada por uma construção coletiva que orienta a formação e o trabalho profissional (PRATES et al., 2012).

Nessa ótica, as propostas dos Cursos de Mestrado e Doutorado devem atender a um conjunto de quesitos para seu pleno funcionamento, dentre os quais, se sobreleva a clareza e a consistência do projeto pedagógico, que dispõe de componentes como: as áreas de concentração, as linhas e os projetos de pesquisa, a estrutura curricular, a ementa de disciplinas e a forma de seleção e admissão de candidatos, levando-se em conta o perfil da formação profissional almejada e a fase de desenvolvimento da área. (BRASIL, 2003).

Diante dos elementos indicados, privilegiou-se a análise das matérias/conteúdos providos no processo de formação pós-graduada em Serviço Social, no sentido de 
apreender a direção social presente neste nível de ensino, tendo em vista que a estruturação e o desenvolvimento de um projeto pedagógico não se reduzem às disciplinas que compõem as matrizes curriculares dos Cursos de PPGSS. Isso significa que:

[...] o currículo, longe de se constituir uma simples justaposição de conteúdos programáticos, é a expressão de um conjunto de concepções, é a explicitação de tendências políticas, teóricas e metodológicas que são imanentes à direção social que se deseja imprimir a um projeto de formação profissional, incorporado num projeto educacional de curso (ANDRADE, 2000, p. 4).

Dessa forma, adverte-se que a apreciação das ementas e das tendências teóricas, predominantes nos conteúdos das disciplinas, requisita um minucioso exame dos dados constantes na organização curricular dos cursos, o que será tratado em outra produção, pois fuge ao alcance deste trabalho. Diante das informações sistematizadas no Banco de Dados, com base na Plataforma Sucupira (2016), identificou-se as tendências das temáticas prevalecentes na estruturação dos currículos dos Mestrados Acadêmicos e Doutorados em Serviço Social das IES, que preveem uma carga horária mínima ${ }^{10}$ para a titulação, a ser contemplada através de disciplinas obrigatórias e/ou eletivas/optativas e outros requisitos curriculares (como a defesa da dissertação/tese). Assim, a análise centra-se nas tendências temáticas constantes na denominação das disciplinas obrigatórias. $\mathrm{O}$ ressalto, nessas disciplinas, justifica-se pelo fato de que compõem o principal núcleo articulador da formação e da produção de conhecimentos, em nível de pós-graduação.

Frisa-se, ainda, que um dos quesitos que orientam a avaliação dos PPGSS é a busca pela articulação entre pós-graduação e graduação, tendo em vista a contribuição para a formação de profissionais mais capacitados nos plano da graduação (CAPES, 2013). Isto implica, igualmente, levar em conta a importância da formação de docentes com competências para efetivar o projeto de formação profissional presente nas diretrizes da Associação Brasileira de Ensino e Pesquisa em Serviço Social e Centro de Documentação e Pesquisa em Políticas Sociais e Serviço Social- (1996). Desse modo, entende-se que as disciplinas obrigatórias de mestrado e doutorado constituem um espaço privilegiado para

\footnotetext{
${ }^{10}$ A duração prevista dos cursos stricto sensu é de, no mínimo, um (01) ano para o mestrado e dois (02) anos para o doutorado, sendo a permanência máxima nos cursos definida pelos regimentos dos programas de pós-graduação (BRASIL, 1983). No entanto, a Coordenação de Aperfeiçoamento de Pessoal de Nível Superior (2014) pontua que o mestrado perdura, em média, dois (02) anos, e o doutorado, quatro (04) anos.
} 
o adensamento das bases teórico-metodológicas e ético-políticas que sustentam os eixos fundamentais desta proposta de formação.

No universo de vinte e um (21) PPGSS, foram abarcados, na amostra, doze (12), pois nove (09) programas ${ }^{11}$ não possuem disciplinas obrigatórias, contando, somente, com disciplinas eletivas/optativas. Embora a flexibilidade curricular seja um critério que orienta a avaliação dos PPGSS, que figura como tendência internacional da pós-graduação mesmo com o número crescente de profissionais de outras áreas que participam dos cursos de mestrado e doutorado em Serviço Social -, é fundamental que a formação básica, composta pelas disciplinas obrigatórias, contemple a abordagem da própria profissão e as diferentes análises teórico-metodológicas sobre seu significado social, de modo a recuperar a trajetória da mesma, no contexto da sociedade brasileira, e a produção de conhecimento do Serviço Social. Tal perspectiva não implicaria em uma rigidez curricular, mas se articularia com disciplinas optativas que oferecem suporte para as áreas e linhas de pesquisa. Destaca-se que este é um ponto bastante polêmico, mas que não pode deixar de ser contemplado e necessita ser discutido, coletivamentamente, em fóruns da Associação Brasileira de Ensino e Pesquisa em Serviço Social (ABEPSS).

$\mathrm{Na}$ organização das matrizes curriculares, registrou-se um total de quarenta e cinco (45) disciplinas obrigatórias e de quatrocentos e oitenta e quatro (484) optativas para o Mestrado Acadêmico. Já no que tange aos cursos de Doutorado, foram identificadas dezoito (18) obrigatórias e trezentos e quarenta e nove (349) disciplinas optativas. A comparência de conteúdos dos créditos obrigatórios foram categorizadas nos Quadros 4 e 5.

Quadro 4 - Especificação das temáticas nas disciplinas obrigatórias do mestrado

\begin{tabular}{|l|l|c|}
\hline \multicolumn{1}{|c|}{ Especificação das temáticas } & \multicolumn{1}{|c|}{ Programas em que a temática está presente } & Freq. \\
\hline Serviço Social & $\begin{array}{l}\text { PUC-GOIÁS, UFPB/J.P (2), UEPB, UFAM, UFJF, PUCRJ (2), } \\
\text { UFSC, UNIOESTE, PUCRS. }\end{array}$ & 11 \\
\hline $\begin{array}{l}\text { Política(s) Pública(s)/ Política (s) } \\
\text { Social(is) }\end{array}$ & $\begin{array}{l}\text { PUC-GOIÁS, UFPB/J.P (2), UEPB, UFJF, PUCRJ, UNIOESTE, } \\
\text { PUCRS. }\end{array}$ & 08 \\
\hline Estado & UEPB, UFPE, UFJF, PUCRS, UFPB/J.P, UFAM & 06 \\
\hline $\begin{array}{l}\text { Direitos sociais/Direitos/ Direitos } \\
\text { Humanos }\end{array}$ & UFPB/J.P, UFAM, UEPB, UFPE, PUCRJ, UNIOESTE. & 06 \\
\hline Pesquisa/ Metodologia Científica & UFAM (2), PUCRJ, UFJF, UFSC, PUCRS. & 06 \\
\hline Dissertação & UFAM (2), PUCRJ, UFJF & 04 \\
\hline
\end{tabular}

\footnotetext{
${ }^{11}$ Quais sejam: UFPA, UFF, UECE, UFRN, UFAL, FUFSE, UNESP/FR, PUCSP, UFRJ.
} 


\begin{tabular}{|l|l|c|}
\hline $\begin{array}{l}\text { Fundamentos/Fundamentação do } \\
\text { Serviço Social }\end{array}$ & UEPB, UNIOESTE, UFAM & 03 \\
\hline Questão Social & UFJF, PUCRJ, PUCRS. & 03 \\
\hline Temáticas com menor incidência $^{12}$ & UFAM (2), PUC-GOIÁS, UERJ & 04 \\
\hline Temáticas com frequência única $^{13}$ & UFPB/J.P (2), UEPB, UFAM, UFJF (5), PUCRS (2) & 11 \\
\hline
\end{tabular}

Fonte: Sistematização das autoras a partir da Plataforma Sucupira (2016).

Concernente às disciplinas obrigatórias do mestrado, verificou-se, nos títulos, a predominância de dois (02) assuntos: Serviço Social, com repetição de onze (11) vezes; e Políticas/Política(s) Pública(s)/Política (s) Social(is), com oito (08) vezes. Desse modo, estes são os dois eixos temáticos centrais dos cursos de mestrado. A seguir, emergem respectivamente: Estado (06), Direitos Sociais/Direitos/Direitos Humanos (06), Dissertação (04); Pesquisa/Metodologia Científica (06), Dissertação (04), Fundamentos/Fundamentação do Serviço Social (03) e Questão Social (03). Os dados apresentados indicam uma tendência inversa à ocorrência nas áreas de concentração e linhas de pesquisa dos programas, em que o tema Políticas/Política(s) Pública(s)/Política (s) Social(is) é priorizado ao invés do Serviço Social.

Além disso, averigou-se que os PPGSS têm privilegiado, na organização curricular, a abordagem do Serviço Social, sendo que a concentração de disciplinas sobre a profissão se dá nos PPGSS das regiões Nordeste (03), Sudeste (03) e Sul (03) do país, o que, sem dúvida, merece melhores investimentos em termos de estudos no sentido de identificar a relação entre as matérias ofertadas, as pesquisas efetivadas nos programas de pós-graduação e o acúmulo de produção de conhecimento (livros, artigos, teses, dissertações, entre outros) sobre o Serviço Social nessas regiões.

Outro aspecto que deve ser observado é o destaque para o Serviço Social como assunto prevalecente nos PPGSS, que tende a indicar uma centralidade atribuída ao debate contemporâneo da profissão, em temas como: as transformações societárias e os impactos nos processos de formação e exercício profissional; as novas exigências teóricas, metodológicas e operacionais postas aos processos de formação profissional; as condições concretas para o desenvolvimento do trabalho profissional; a inserção e o trabalho do/a assistente social nos diferenciados espaços sócio-ocupacionais; o objeto da intervenção

\footnotetext{
${ }^{12}$ As temáticas com menor constância são: Trabalho (2) e Amazônia (2).

${ }^{13}$ Quais sejam: Nordeste, ciência política, gênero, atividades programadas, sustentabilidade, transformações societárias, sociologia clássica, território, sociedade, movimentos sociais.
} 
profissional (a questão social em suas múltiplas expressões); a ética profissional em suas várias formas de expressão; o projeto ético-político, seu estado atual e desafios; as principais tendências históricas e teórico-metodológicas da profissão, entre outros.

Mantém-se, também, como tema predominante (2ㅇ lugar), as Política(s) Pública(s)/ Política (s) Social(is), que tem correspondência direta com as áreas de concentração e linhas de pesquisa dos PPGSS. Isso vai ao encontro da análise de lamamoto (2008) sobre a produção de conhecimentos e investigações da pós-graduação, que aponta para uma concentração significativa (41\%) nas "Políticas Sociais: Estado e Sociedade Civil", com proeminência na organização, gestão e operacionalização de programas e projetos ofertados nas políticas sociais em âmbito estadual e municipal. Assim, parece elementar e necessário dizer que a "política social", além de ser uma das matérias básicas das diretrizes curriculares do Serviço Social (ABEPSS, 1996), é "uma das mediações mais importantes para o trabalho profissonal." (COUTO, 2004, p. 43).

Além disso, é preciso referir que, ao longo de seu desenvolvimento e solidificação, enquanto profissão, o Serviço Social tem sido requesitado para a prestação de serviços, programas, projetos e benefícios previstos pelas políticas sociais públicas (saúde, assistência social, previdência social, habitação, entre outras). As discussões, as reflexões e os conhecimentos produzidos sobre o tema vêm crescendo no debate crítico da área, desde meados da década de 1980, sendo impulsionado pela conjuntura de redemocratização e de formulação constituinte (BEHRING; BOSCHETTI, 2007) e pela consolidação/profissionalização das políticas sociais públicas nas últimas décadas. Ademais, deve-se ter em vista a expansão desse campo de trabalho profisssional, que traz a necessidade de se efetivar estudos e pesquisas sobre o tema para o enfrentamento dos limites/desafios postos à profissão e à formação.

Em relação aos demais assuntos, especialmente, a "Questão Social", os dados sugerem um reduzido trato dessa matéria, ao passo que a temática Estado se sobressai na estruturação das disciplinas obrigatórias de mestrado. Isso gera indagação, pois a questão social, em suas várias manifestações: i) constitui a base da fundação sócio-histórica do Serviço Social como uma especialização do trabalho coletivo; ii) explica a necessidade das políticas sociais (IAMAMOTO, 2005); iii) e compõe uma das matérias básicas das diretrizes curriculares, além de ser eixo orientador da formação (ASSOCIAÇÃO BRASILEIRA DE ENSINO 


\section{E PESQUISA EM SERVIÇO SOCIAL; CENTRO DE DOCUMENTAÇÃO E PESQUISA EM POLÍTICAS} SOCIAIS E SERVIÇO SOCIAL, 1996), desse modo, questiona-se: Como a questão social pode não ser o ponto estruturador das discussões e da produção de conhecimentos na PósGraduação em Serviço Social?

É evidente que se reconhece os contínuos investimentos do Serviço Social para atribuir densidade teórica ao trato da questão social, sob orientação da teoria social crítica de Marx e da tradição marxista, que, desde a década de 1990, tem registrado contribuições consistentes em distintos aspectos. Os referenciais teóricos e bibliográficos produzidos mostram "não existir unicidade na compreensão da questão social no amplo marco da tradição crítica do Serviço Social brasileiro, ainda que haja um consenso majoritário quanto à sua centralidade para o Serviço Social." (IAMAMOTO, 2008, p. 186). Isso reforça a necessidade de investimentos em estudos sobre a questão social, uma vez que os/as assistentes sociais são, cotidianamente, desafiados a analisar (interpretativa e explicativamente) e a intervir nas configurações e manifestações por ela assumidas na sociedade capitalista contemporânea.

Isso exige que a formação profissional tenha, como pilar de estruturação de seus currículos, uma determinada orientação teórico-metodológica.

\footnotetext{
Mas isso não significa falar de qualquer modo de pesquisar, ou de ver os sujeitos, a sociedade, a ciência, porque dependendo do projeto ético-politico que orienta nossa leitura e intervenção, que orienta nossas investigações, como elementos que compõem esse processo, podemos ter escolhas diversas, finalidades diversas, e conseqüentemente, podem ser diversos nossos modos de fazer, de trabalhar com o dado, de valorizá-lo, de relacioná-lo, de utilizá-lo, de socializá-lo. Estas questões são questões de método. Método - como conjunto de valores, teorias, paradigma epistemológico que orientam nossas investigações; e método ou metodologia - como caminho, como o modo de fazer, como escolha de instrumentos, técnicas de coleta e análise [...] (PRATES, 2005, p. 132).
}

Desse modo, a teoria social crítica de Marx e o método materialista histórico e dialético devem estar presentes, transversalmente, em todo o currículo dos cursos de mestrado e doutorado, como subsídio heurístico a orientar a formação profissional, a leitura de realidade e a intervenção social, o desvendamento do objeto profissional (a questão social em suas múltiplas manifestações), a compreensão da sociedade capitalista e a explicação sobre "o conjunto de desigualdades que caracterizam o contexto 
contemporâneo no intuito de subsidiar estratégias para o seu enfrentamento e as diversas formas de resistência construídas pelos sujeitos sociais [...]" (PRATES, 2005, p. 131).

Nessa mesma direção, três elementos da teoria social crítica de Marx são considerados fundamentais, pois se relacionam com o debate sobre a produção de conhecimentos em uma área interventiva como o Serviço Social:

[...] a centralidade da práxis na transformação da realidade, e, portanto a unidade entre teoria e prática; o movimento do método dialético-crítico que implica a passagem e conexão entre singularidade e universalidade; e a indissociabilidade entre método e valor, ou seja, não há neutralidade na produção do conhecimento porque o método, em unidade com a teoria e como movimento desta, exprime uma necessária valoração dos processos sociais, uma dada forma de leitura da realidade (CLOSS, 2015, p. 194-195).

Em relação ao primeiro elemento (CLOSS, 2015), é necessário explicitar que a perspectiva da práxis implica a superação tanto do teoricismo como do praticismo, pois a centralidade da análise da realidade em suas contradições e, portanto, em suas possibilidades latentes de mudança e intervenção, afirma a relação entre teoria e prática como essencial à lógica dialética. Esta lógica visa, sobretudo, a "superar os limites do realizado, na esperança ou na expectativa de um futuro outro que não o presente. Quando ela se perde no ideal abstrato, recorda-Ihe que a ideia e o ideal saem do real e devem a ele retornar através da realização prática" (LEFEBVRE, 1979, p. 210).

Desse modo, a pesquisa e a produção de conhecimentos, realizadas sob a orientação da teoria social crítica, vinculam-se, necessariamente, à transformação da realidade social, uma vez que "é na práxis que o homem precisa provar a verdade, isto é, a realidade e a força, a terrenalidade do seu pensamento" (MARX; ENGELS, 1998, p. 100). Em outras palavras, a centralidade da práxis pressupõe a unidade-diversidade entre teoria e prática, implica uma articulação na qual a realidade enfrentada no exercício profissional forneça elementos para que a razão teórica se debruce sobre questões concretas, sendo a pesquisa um ingrediente imprescindível para a produção de conhecimentos que subsidiem alternativas a serem praticadas, o que não significa a aplicação de um receituário que as "solucione" imediatamente (SILVA, 2007).

No que se refere ao segundo elemento (CLOSS, 2015), o movimento do método na análise da realidade, este, ao ultrapassar a imediaticidade e voltar-se à apreensão do 
concreto "como síntese de múltiplas determinações, isto é, unidade do diverso" (MARX, 2007 , p. 256), possibilita a valorização de aspectos singulares, sem deslocá-los do contexto mais amplo que os condiciona, pois a abordagem de um objeto de estudo, sob a lógica dialética, implica tanto focar sua particularidade como situá-lo num conjunto de relações por meio de totalizações provisórias (LEFEBVRE, 1979). O desafio reside, portanto, em atribuir visibilidade a esse conjunto de relações, de forma a transitar da apreensão mais ampla e totalizante da realidade ao exercício da profissão em seu tempo miúdo, como ressalta Yazbek (2005), para que este mesmo trânsito possibilite trabalhar a universalidade contida nas situações singulares vividas no cotidiano. A riqueza e a complexidade do papel da pesquisa, sob essa perspectiva, estão na possibilidade de se "reconstruir mediações (conexões) que revelam como o universal se particulariza em uma determinada singularidade e de que forma esta singularidade contém o universal e é influenciada por ele" (SILVA, 2007, p. 291).

O terceiro elemento (CLOSS, 2015) consiste na afirmação de que, no âmbito da teoria social crítica de Marx, não há neutralidade na ciência, pois todo conhecimento é social, sendo fundamental considerar seus vínculos com o poder e a disputa de hegemonia (YAZBEK, 2005). Esta perspectiva afirma a possibilidade de se construir pesquisas comprometidas com a superação das desigualdades, que desocultem a questão social em suas múltiplas expressões, contrapondo-se à banalização do humano e dando visibilidade a resistências, lutas e rebeldias sociais que se desenvolvem no cotidiano da vida social, não se contentando com a superfície e aparência da realidade, tampouco com o fragmento. Portanto, essa é uma produção do conhecimento mobilizada pelos valores constituintes do projeto ético-político profissional e atenta à natureza interventiva da profissão, que fornece uma base empírica de extrema riqueza, embora, por si só, sem reconstrução crítica, não seja suficiente para iluminar e ampliar as potencialidades de ação. Assim, tal reconstrução é função precípua da pesquisa que tem como horizonte a produção de conhecimentos que ajudem a fundamentar, teoricamente, o desenvolvimento de processos emancipatórios (YAZBEK, 2005).

Do exposto, pode-se inferir que a teoria social crítica e a tradição marxista devem balizar os conteúdos das disciplinas curriculares dos cursos de pós-graduação em Serviço 
Social, fornecendo densidade crítica a temáticas centrais, como: políticas sociais públicas, questão social, trabalho e processos de trabalho e análise da própria profissão.

Por fim, do universo da organização curricular, cumpre citar a diversidade de temas postos (gênero, território, sustentabilidade etc), a partir das disciplinas obrigatórias de mestrado, especialmente, as que apresentaram frequência menor ou mesmo única, o que sinaliza uma formação diversa entre os PPGSS e se relaciona, sobretudo, com as linhas e grupos de pesquisa existentes nas IES.

Chama especial atenção, entre as matérias com menor frequência, a de Fundamentos do Serviço Social, pois a mesma não aparece em uma posicão de prioridade nas disciplinas que compõem os currículos dos cursos de mestrado. Tal tendência, também identificada nas disciplinas obrigatórias de doutorado, pode estar relacionada à existência de pequenos estudos sobre o tema na atualidade. Com base na pesquisa realizada por Closs (2015), verifca-se que a produção que aborda, diretamente, os Fundamentos, é bastante diminuta, não atingindo $1 \%$ das publicações dos periódicos de Serviço Social (0,49\%), e que a totalidade de artigos que trata de temáticas relativas aos Fundamentos também é reduzida $(15,91 \%)$, destacando-se a predominância da abordagem dos Fundamentos com ênfase na historicidade e no trabalho profissional, seguida pelas produções sobre teoria/método/marxismo e questão social. Logo, infere-se que há uma correlação entre as tendências de publicações dos periódicos e a estruturação da pós-graduação em Serviço Social.

Os resultados aportados por Closs (2015) encontram-se relacionados com as análises efetuadas por lamamoto (2008), que indicaram que a temática dispõe de pouca representatividade nas produções do Serviço Social. Assim, é preciso considerar que as investigações e as pesquisas sobre temas diversos, no campo das ciências humanas e sociais, não excluem a necessidade do Serviço Social realizar estudos que tratem dos fundamentos da profissão. Ocorre que a hipótese levantada por Pagaza $(2009$, p. 183, livre tradução) é a de que "as investigações sobre os fundamentos do trabalho profissional estão estancadas porque abordam temas referidos às ciências sociais em geral desconectados dos aportes que se podem realizar a profissão." Com isso, não se está negando a importância da realização de investigações e pesquisas sobre outros temas, no entanto, deve-se ter cuidado para não se correr o risco de se supervalorizar matérias de formação 
genérica (assim como as específicas). A ideia é assegurar o diálogo, a articulação e a complementação de conteúdos particulares do Serviço Social e de outras matérias.

Assim, segue a discussão a respeito dos Cursos de Doutorado, que, do total de vinte e um (21) PPGSS, apenas dez (10) possuem este nível de curso. A partir das informações da Plataforma Sucupira (2016), registrou-se um total de vinte e cinco (25) disciplinas obrigatórias para o Doutorado, categorizadas de acordo com o Quadro 5 a seguir.

Quadro 5 - Especificação das temáticas nas disciplinas obrigatórias do doutorado

\begin{tabular}{|l|l|c|}
\hline \multicolumn{1}{|c|}{ Especificação das temáticas } & \multicolumn{1}{c|}{ IES } & Freq. \\
\hline Pesquisa & UNESP/FR, UFSC, PUCRS (3) & 05 \\
\hline Tese & UNESP/FR, PUCRJ (4) & 05 \\
\hline Serviço Social & PUCRJ, UFSC, PUCRS (2) & 04 \\
\hline Estado & UFPE, PUCRJ, PUCRS & 03 \\
\hline Temáticas com menor incidência ${ }^{14}$ & UFPE, PUCRJ (3) & 04 \\
\hline Temáticas com frequência única ${ }^{15}$ & PUCRS (3), UFPE & 04 \\
\hline
\end{tabular}

Fonte: Sistematização das autoras a partir da Plataforma Sucupira (2016).

Identificou-se que as temáticas voltadas à investigaticação - "Pesquisa" e Tese" - são as predominantes, com ocorrência de dez (10) vezes, seguidas da ênfase para a profissão (04) e o Estado (03). Estes dados reafirmam a incorporação da investigação como dimensão constitutiva da formação, do trabalho dos (as) assistentes sociais e da produção de conhecimentos, ou seja, mesmo diante de sua presença nos currículos dos cursos de mestrado e doutorado, entende-se que a pesquisa possui um caráter de transversalidade no universo total das disciplinas. Sob estas demarcações, reafirma-se a pesquisa como condição necessária e essencial para a formação e o exercício profissional dos (as) assistentes sociais, pois, ao se qualificar o ser e o fazer profissional também se produz conhecimentos e se contribui para a construção da própria profissão, bem como, para a transformação da realidade social.

Nesse sentido, é importante registrar o caráter formativo da pesquisa, que propicia: o aprimoramento das competências, habilidades e atitudes profissionais; a unidade teoriaprática; a articulação entre a formação para a intervenção e a formação para a produção

\footnotetext{
${ }^{14}$ Quais sejam: Estágio Docente (2) e Sociedade (2).

${ }^{15}$ Compreendem: Direitos, Fundamentos, Economia, Mercado.
} 
de conhecimentos; o permanente diálogo entre o pensamento crítico contemporâneo e a realidade social; a construção de estratégias adequadas no enfrentamento da questão social; o reexame dos objetivos e procedimentos, das evidências e dos saberes; o exercício de ações conjugadas entre diferentes sujeitos (profissionais e pesquisadores) das diversas áreas do saber; a produção e a troca de saberes; e a construção de conhecimentos inovadores e críticos, dentre outros.

As demais disciplinas, como pode ser visualizado no Quadro 5, reforçam a tendência de abordagem do "Estado" e do "Serviço Social", tal como nas disciplinas de mestrado, destacando-se a ausência do tema "Política Social/Pública". O pequeno universo de disciplinas obrigatóricas, na formação em nível de doutorado, indica uma flexibilidade no currículo, que oportuniza a produção de estudos/pesquisas voltados aos objetos de investigação dos discentes, em articulação com as linhas e os grupos de pesquisa dos PPGSS.

\section{Conclusão}

Por meio da presente análise, foi possível concluir que a investigação e a formação pós-graduada sobre políticas sociais e públicas vêm ocupando uma posição protagonista nas áreas de concentração dos PPGSS, bem como, nas linhas de pesquisa. Este dado se explica, sobretudo, pelo vínculo histórico existente entre a profissão e as políticas sociais, espaço onde mais atuam os assistentes sociais, assim como, pelo protagonismo político assumido pela profissão na luta e defesa dos direitos sociais.

Contudo, há que se ponderar que essa crescente abordagem, nos PPGSS - embora a área conte com uma significativa pós-graduação em Política Social -, necessita estar acompanhada do adensamento do debate teórico-metodológico sobre a própria profissão, especialmente, no que se refere aos seus Fundamentos, tendo em vista a formação de docentes que materializem o projeto de preparação profissional previsto nas Diretrizes Curriculares da ABEPSS.

No âmbito das linhas de pesquisa, há uma predominância também para o estudo do tema da Política Social, seguida da ênfase para o" Trabalho/Processos de Trabalho", juntamente com a existência de uma grande variação de temas que permeiam o exercício profissional do assistente social, por exemplo, os direitos sociais, a questão social, os 
movimentos sociais, o Estado, entre outros. A presença dessas temáticas indica uma preocupação com a formação de mestres e doutores com competências para a intervenção e produção de conhecimentos sobre a realidade social e sobre as demandas emergentes do próprio trabalho profissional.

A análise da oferta de disciplinas obrigatórias evidencia a diversidade de conteúdos que orientam as matrizes curriculares nos cursos de Mestrado e Doutorado, articuladas às linhas e grupos de pesquisas das IES. Nesse contexto, identifica-se uma forte incidência dos temas, Política(s) Pública(s)/ Política (s) Social(is) e Estado, no âmbito da formação de mestrado, ao passo que, no doutorado, a maior ênfase é atribuida à investigação. Contudo, do mesmo modo, merecem destaque as disciplinas particulares ao Serviço Social, relacionadas ao trabalho, à questão soicial, à formação e ao arcabouço teóricometodológico e ético-político da profissão.

De modo geral, a diversidade de disciplinas ofertadas abarca um amplo leque de matérias que explicitam a direção social de uma formação pós-graduada voltada para o desvendamento da realidade social, compreendendo o estudo sobre a própria profissão nas suas múltiplas dimensões e determinações na realidade societária contemporânea, de modo a contribuir para a elaboração de respostas às demandas sociais enfrentadas no cotidiano profissional.

A partir do debate realizado e diante das questões analisadas, é imprescindível demarcar que, na conjuntura atual, são muitos os desafios e mesmo as limitações impostas para a formação pós-graduada, a pesquisa e a produção de conhecimento orientadas pela perspectiva crítica no cenário da universidade brasileira, marcado por tendências regressivas, privatistas, pela lógica mercantil, produtivista e de "sustentabilidade", o que não pode deixar ser destacado, mas não foi aprofundado, por ser amplamente debatido pela profissão.

Em termos mais explícitos, como sinaliza Silva (2007), deve-se fazer o enfrentamento aos processos de mercantilização, na esfera das instituições de ensino, da formação profissional e do financiamento à pesquisa, por meio de uma luta vinculada à democracia, essencial à consolidação de uma massa crítica e da efetivação do projeto ético-político que orienta a formação e o exercício profissional para um trabalho compromisssado com a socialização do saber e que tenha como horizonte a emancipação humana (MARX, 2009). 
Além disso, é fundamental que se viabilize espaços favorecedores da constante interlocução entre os centros de produção de conhecimento e os profissionais que atuam em diversos espaços sócio-ocupacionais, tendo em vista a contribuição da pós-graduação para a formação graduada e permanente dos/das assistentes sociais (CLOSS, 2015).

Finaliza-se esta produção científica demarcando que se trata de uma totalização provisória, que será adensada em outros trabalhos científicos, pelo Grupo de Estudos sobre Teoria Marxiana, Ensino e Políticas Públicas (GTEMPP). Registra-se que o desenvolvimento da pesquisa e a proposição de novos estudos resultaram em novos projetos sobre a direção da pós-graduação no Brasil e a contribuição dos núcleos e grupos de pesquisa, bem como, sobre a direção social da pós-graduação em Serviço Social no Brasil e na Argentina.

\section{Referências}

ABREU, M. M. Serviço social e organização da cultura: perfis pedagógicos da prática profissional. São Paulo: Cortez, 2002.

. Pesquisa em serviço social: tendências na implementação das diretrizes curriculares. Temporalis: Revista da Associação Brasileira de Ensino e Pesquisa em Serviço Social, Brasília, ano 7, n. 14, jul./dez. 2007.

ANDRADE, M. A. R. A. O ensino superior e o ensino no curso de serviço social. Serviço Social em Revista, Londrina, v. 2, n. 2, jan./jun. 2000. Disponível em:

<http://www.uel.br/revistas/ssrevista/c_v2n2_ensino.htm>. Acesso em: 1 jul. 2014.

ASSOCIAÇÃO BRASILEIRA DE ENSINO E PESQUISA EM SERVIÇO SOCIAL - ABEPSS; CENTRO DE DOCUMENTAÇÃO E PESQUISA EM POLÍTICAS SOCIAIS E SERVIÇO SOCIAL-CEDEPSS. Currículo mínimo para o curso de serviço social. Rio de Janeiro: ABESS; CEDEPSS, 1996.

BEHRING, E. R.; BOSCHETTI, I. Política social: fundamentos e história. 2. ed. São Paulo: Cortez, 2007.

BORÓN, A. Império \& imperialismo: una lectura crítica de Michael Hardt y Antonio Negri. 4. ed. Buenos Aires: CLACSO, 2003. (Colección de ciencias sociales de la secretaría ejecutiva de Calcso).

BRASIL. Conselho Federal de Educação. Resolução no 05, de 10/03/83. Fixa normas de funcionamento e credenciamento dos cursos de pós-graduação stricto sensu. Disponível em:

<https://www.capes.gov.br/images/stories/download/legislacao/Resolucao_CFE_05_198 3.pdf>. Acesso em: 1 jul. 2014.

BRASIL. Decreto no 7.692, de 2 de março de 2012. Aprova o Estatuto e o Quadro Demonstrativo dos Cargos em Comissão da Coordenação de Aperfeiçoamento de Pessoal 
de Nível Superior - CAPES, e remaneja cargos em comissão. Disponível em: <http://www.planalto.gov.br/ccivil_03/_Ato2011-2014/2012/Decreto/D7692.htm>. Acesso em: 5 maio 2014.

BRASIL. Ministério da Educação. Portaria no 10, de 16 de abril de 2003. Fixa normas e procedimentos para a avaliação anual de propostas de cursos de mestrado e doutorado. Disponível em:

<https://www.capes.gov.br/images/stories/download/legislacao/Portaria_CAPES_010_20 03.pdf>. Acesso em: 27 jun. 2014.

CABRAL NETO, A.; CASTRO, A. M. D. A. A expansão da pós-graduação em cenários de globalização: recortes da situação brasileira. Revista Inter-Ação, Goiânia, v. 38, n. 2, p. 339-362, maio/ago. 2013.

IAMAMOTO, M. V.; CARVALHO, R. de. Relações sociais e serviço social no Brasil: esboço de uma interpretação histórico-metodológica. 16 ed. São Paulo: Cortez, 2012.

CLOSS, T. T. Fundamentos do serviço social: um estudo a partir da produção da área. 2015. 253 f. Tese (Doutorado em Serviço Social) - Pontifícia Universidade Católica do Rio Grande do Sul, Porto Alegre, 2015.

COORDENAÇÃO DE APERFEIÇOAMENTO DE PESSOAL DE NÍVEL SUPERIOR - CAPES. AcesSO à informação: perguntas frequentes pós-graduação. Disponível em:

$<$ http://www.capes.gov.br/acesso-ainformacao/perguntas-frequentes/posgraduacao/3020-quanto-tempo-em-media-e-a-duracao-de-uma-pos-graduacao >. Acesso em: 1 jul. 2014.

. Documento da área de Serviço Social. Disponível em:

<http://www.capes.gov.br/images/stories/download/avaliacaotrienal/Docs_de_area/Ser vi\%C3\%A7o_Social_doc_area_e_comiss\%C3\%A3o_16out.pdf.> Acesso em: 20 set. 2015.

COUTINHO, C. N. Contra a corrente: ensaios sobre democracia e socialismo. São Paulo: Cortez, 2000.

COUTO, B. R. As diretrizes curriculares e a política social. Temporalis: Revista da Associação Brasileira de Ensino e Pesquisa em Serviço Social, Brasília, ano 4, n. 8, jul./dez. 2004.

IAMAMOTO, M. V. O serviço social na contemporaneidade: trabalho e formação profissional. 9. ed. São Paulo: Cortez, 2005.

IAMAMOTO, M. V. Serviço social em tempo de capital fetiche: capital financeiro, trabalho e questão social. 2. ed. São Paulo: Cortez, 2008.

KAMEYAMA, N. A trajetória da produção de conhecimentos em serviço social avanços e tendências (1975 a 1997). 1998. Disponível em:

<http://www.ts.ucr.ac.cr/binarios/congresos/reg/slets/slets-016-088.pdf >. Acesso em: 27 out. 2015.

LEFEBVRE, H. Lógica formal, lógica dialética. Rio de Janeiro: Civilização Brasileira, 1979. 
MARTINELLI, M. L. Serviço social: identidade e alienação. São Paulo: Cortez, 2003.

MARX, K. Contribuição à crítica da economia política. 2 ed. São Paulo: Expressão Popular, 2007.

. Para a questão judaica. São Paulo: Expressão Popular, 2009.

. ENGELS, F. A ideologia alemã. Teses sobre Feuerbach. São Paulo: Martins

Fontes, 1998.

NETTO, J. P.. Ditadura e serviço social: uma análise do Serviço Social no pós-64. 7 ed. São Paulo: Cortez, 2004.

. Capitalismo monopolista e serviço social. São Paulo: Cortez, 2011.

PAGAZA, M. R. Servicio social: fundamentos, formación y trabajo profesional. Temporalis: Revista da Associação Brasileira de Ensino e Pesquisa em Serviço Social, Brasília, n. 18, 2010.

PLATAFORMA SUCUPIRA. Informações do programa. Disponível em:

$<$ https://sucupira.capes.gov.br/sucupira/public/informacoes_programa/informacoesProg rama.jsf>. Acesso em: 21 jun. 2016.

PRATES, J. C.. O método e o potencial interventivo e político da pesquisa social.

Temporalis, Brasília, v. 09, 2005.

. Desafios à formação e ao trabalho profissional num contexto de crise.

Textos \& Contextos, Porto Alegre, v. 14, n. 1, p. 1-8, jan./jun. 2015.

PRATES, J. C. et al. Pesquisa e formação na pós-graduação. In: ENCONTRO NACIONAL DE PESQUISADORES EM SERVIÇO SOCIAL, 13., 2012, Juiz de Fora. Anais... Juiz de Fora, 2012.

RAMOS, S. R. A prática na formação profissional em Serviço Social: tendências e dificuldades. Temporalis: Revista da Associação Brasileira de Ensino e Pesquisa em Serviço Social, Brasília, ano 7, n. 14, jul./dez. 2007.

SANTOS, J. S. Particularidades da "questão social" no Brasil: mediações para seu debate na "era" Lula da Silva. Revista Serviço Social e Sociedade, São Paulo, n. 111, p. 430-449, jul./set. 2012.

SILVA E SILVA, M. O.; CARVALHO, D. B. B. A pós-graduação e a produção de conhecimento no Serviço Social brasileiro. Revista Brasileira de Pós-Graduação, Brasília, v. 4, n. 8, p. 192216, dez. 2007. Disponível em:

<http://www2.capes.gov.br/rbpg/images/stories/downloads/RBPG/Vol.4_8dez2007_/Est udos_artigo1_n8.pdf>. Acesso em: 28 out. 2015.

SILVA E SILVA, M. O.; CARVALHO, D. B. B; ROSA, M. J. M. ; MIOTO, R. C. T. A pesquisa, a produção e a divulgação de conhecimento dos programas de Pós-graduação na área de Serviço Social. In: CARVALHO, D. B. B.; SILVA E SILVA, M. O. (Org.). Serviço social, pósgraduação e produção de conhecimento no Brasil. São Paulo: Cortez, 2005. 
SILVA; J. F. S. Pesquisa e produção do conhecimento em serviço social. Textos e Contextos, Porto Alegre, v. 6, n. 2, 2007. Disponível em:

http://revistaseletronicas.pucrs.br/fass/ojs/index.php/fass/article/view/2319. Acesso em: 12 abr. 2013.

SILVA, R. S. A formação profissional crítica em serviço social inserida na ordem do capital monopolista. Revista Serviço Social \& Sociedade, São Paulo, n. 103, p. 405-432, jul./set. 2010.

SIMIONATTO, I. Os desafios na pesquisa e na produção do conhecimento em serviço social. Temporalis: Revista da Associação Brasileira de Ensino e Pesquisa em Serviço Social, Brasília, ano 5, n. 9, jan./jun. 2005.

YAZBEK, M. C. Os caminhos para a pesquisa no serviço social. Temporalis: Revista da Associação Brasileira de Ensino e Pesquisa em Serviço Social, Brasília, n. 9, p. 147-159, jan./jul. 2005.

YAZBEK, M. C. Os fundamentos históricos e teórico-metodológicos do serviço social brasileiro na contemporaneidade. In: CONSELHO FEDERAL DE SERVIÇO SOCIAL - CFESS; ASSOCIAÇÃO BRASILEIRA DE ENSINO E PESQUISA EM SERVIÇO SOCIAL - ABEPSS. ServiçO social: direitos sociais e competências profissionais. Brasília: CFESS/ABEPSS, 2009.

YAZBEK, M. C.; SILVA E SILVA; M. O. S. Das origens à atualidade da profissão: a construção da pós-graduação em serviço social no Brasil. In: CARVALHO, D. B. B.; SILVA E SILVA, M. O. (Org.). Serviço social, pós-graduação e produção de conhecimento no Brasil. São Paulo: Cortez, 2005. 